\title{
Clinical Study \\ Proinflammatory and Oxidative Stress Markers in Patients with Periodontal Disease
}

\author{
Ivan Borges Jr., ${ }^{1}$ Emília Addison Machado Moreira, ${ }^{1}$ Danilo Wilhem Filho, ${ }^{2}$ Tiago Bittencourt de Oliveira, ${ }^{2}$ \\ Marcelo Barreto Spirelle da Silva, ${ }^{3}$ and Tânia Silvia Fröde ${ }^{3}$ \\ ${ }^{1}$ Department of Nutrition, Federal University of Santa Catarina, 88040-970 Florianópolis, SC, Brazil \\ ${ }^{2}$ Department of Ecology and Zoology, Federal University of Santa Catarina, 88040-970 Florianópolis, SC, Brazil \\ ${ }^{3}$ Department of Clinical Analysis, Federal University of Santa Catarina, 88040-970 Florianópolis, SC, Brazil
}

Correspondence should be addressed to Emília Addison Machado Moreira, addison@ccs.ufsc.br

Received 31 January 2007; Revised 23 May 2007; Accepted 25 May 2007

Objective. To evaluate the involvement of proinflammatory and oxidative stress markers in gingival tissue in individuals with chronic periodontitis. Subject and methods. Eighteen subjects were divided in two groups: experimental (age 52.9 \pm 5.0$)$ and control (age $51.1 \pm 9.6$ ). The activities of enzymatic antioxidants such as catalase, glutathione peroxidase (GPx), glutathione S-transferase (GST), glutathione reductase, nonenzymatic antioxidants: total glutathione and reduced glutathione, oxidized glutathione (GSSG), thiobarbituric acid reactive substances (TBARS), and myeloperoxidase activity (MPO) were evaluated in gingival tissues from interproximal sites. Statistical differences between groups were determined by independent Student $t$ test and $P<.05$. Results. Individuals with periodontal disease exhibited a significant increase in the activities of MPO, GPx, GST, and also in TBARS and GSSG levels in gingival tissue compared to the control group $(P<.05)$. Conclusion. The results of the present work showed an important correlation between oxidative stress biomarkers and periodontal disease.

Copyright (c) 2007 Ivan Borges Jr. et al. This is an open access article distributed under the Creative Commons Attribution License, which permits unrestricted use, distribution, and reproduction in any medium, provided the original work is properly cited.

\section{INTRODUCTION}

The inflammatory and immune reactions induced by the bacterial plaque represent the main characteristics of periodontitis, and this disease represents a particularly cogent example of problem arising from the phenomenon [1].

Studies have demonstrated that periodontal disease affects between $10 \%$ and $15 \%$ of the world's population, representing the greatest cause of tooth loss [2].

There is strong evidence that this disease affects a specific, predisposed group of the population that presents an exacerbated inflammatory/immune response to the periodontopathogenic bacteria that accumulate on the teeth and around the gingival tissue, which in turn may lead to tissue damage $[1,3]$.

The exact mechanism of periodontitis development, including the prior agents or mediators involved, is not clear. Periodontitis manifests itself as a multifactor phenomenon, including the generation of reactive oxygen species (ROS) [4].

The strong evidence linking ROS to the pathological destruction of the connective tissue during periodontal disease rests on the presence of neutrophils infiltration as the main event in the host's response to bacterial invasion $[1,5,6]$. Furthermore, hydroxyl radical $\left({ }^{\circ} \mathrm{OH}\right)$ is most active in damaging important molecules such as DNA proteins and lipids, while hydrogen peroxide $\left(\mathrm{H}_{2} \mathrm{O}_{2}\right)$, even not being considered a potent ROS, is capable of crossing the nuclear membrane and also damaging the DNA [7]. Quantitatively, the main source of superoxide anion $\left(\mathrm{O}_{2}{ }^{-}\right)$and other ROS responsible for initiation reactions is the respiratory chain. However, its presence in the periodontal tissue results first and foremost from the activation of phagocytes (neutrophils and macrophages), such as antibacterial agents $[1,5,8]$. It has been suggested that superoxide anion is involved in bone reabsorption which has been corroborated by studies that have demonstrated the presence of this anion in reabsorption zones adjacent to the osteoclasts [9].

The hydroxyl radical is able to initiate a classical chain reaction known as lipid peroxidation leading to the vasodilation production and rat bone reabsorption [8]. An example of the damage caused by hydrogen peroxide is that it can stimulate the phosphorylation of the $\mathrm{NF}_{-} \mathrm{B}-\mathrm{I}_{K} \mathrm{~B}$ complex activating the $\mathrm{NK}-{ }_{K} \mathrm{~B}$ and facilitating nuclear translocation 
and downstream of proinflammatory cytokines, including interleukin-2 (IL-2), interleukin-6 (IL-6), interleukin-8 (IL$8), \beta$-interferon, and tumor necrosis factor- $\alpha$ (TNF- $\alpha$ ) that are very important in the pathogenesis of periodontal disease [10-12].

ROS production is inevitable in all aerobic organisms including humans, who necessarily posses a complex system of antioxidant defense $[8,13]$. If the homeostasis is interrupted in favor of ROS, an oxidative stress situation is created [13].

The aim of this study was to evaluate the involvement of proinflammatory and oxidative stress markers in individuals with chronic periodontal disease.

\section{SUBJECTS AND METHODS}

\subsection{Experimental design}

This case-control study was carried out between MaySeptember, 2003 in a single centre (Peridontologic Centre, Florianopolis, Santa Catarina, Brazil). Eighteen subjects were divided into 2 groups: experimental group (E), comprising individuals with chronic periodontitis, age $52.9 \pm 5.0$ (4 men and 5 women), with the following inclusion criteria: presence of chronic inflammation (pain, redness, heat, swelling), diagnosed according to bleeding on probing, at least 5 or 6 sites with probing depth $\geq 5 \mathrm{~mm}$, attachment loss $\geq 3 \mathrm{~mm}$, and extensive radiographic bone loss [14]. Control group (C), was composed of healthy individuals, age $51.1 \pm 9.6$ (4 men and 5 women) with no prior history of periodontal disease. The probing depth in this latter group did not exceed $3 \mathrm{~mm}$ [14].

For both groups, the following items were considered as exclusion criteria: infection, cardiovascular and/or neurological illness, renal insufficiency and/or diabetes; pregnancy; smoking; use of antibiotics and/or hormonal or nonhormonal anti-inflammatory drugs 6 months prior to tissue collection.

In the day of the surgical procedures, the patients showed no complication.

This study was in agreement with the ethical principles of the World Medical Association Declaration of Helsinki (1964). Permission for this study was obtained from the Ethical Committee for Human Research of the Federal University of Santa Catarina (Project no. 210/2002) and the study included only individuals that agreed to participate after reading and signing a free and informed consent form, except those with difficulty in understanding and communicating, with physical handicap, or both, which could have compromised the sample collection.

\subsection{Assessment of periodontal disease}

All of the surgical procedures were assessed and performed by a periodontist, according to the necessity for each treatment. The patients with chronic periodontitis (experimental group) were submitted a pocket depth reduction technique from palatal/lingual, buccal, and interproximal sites [15]. The biopsies were obtained from inflammatory granulation tissues, connective and epithelium tissues.
The samples collected from the control group were obtained from quarantined mucosa during the surgical procedures of impacted third molars removed following orthodontic recommendation or after the reopening of dental implants.

All samples from the experimental and control groups were removed during the surgical and were immediately frozen in liquid nitrogen $\left(\cong-170^{\circ} \mathrm{C}\right)$ subsequently latter laboratory analysis.

The determinations of the inflammatory parameters were made as scheduled on different days. On the day of the experiments, the samples were deathward at room temperature to determine the different parameters: CAT, GPx, GST, GR, MPO activities, and the contents of TG, GSH, GSSG, and TBARS.

\subsection{Assessment of antioxidants enzymes}

The method described by Aebi was employed to measure the catalase activity (CAT) by measuring the decay of a freshly prepared $10 \mathrm{mM}$ hydrogen peroxide solution at $240 \mathrm{~nm}$ [16].

Glutathione peroxidase (GPx) was measured at $340 \mathrm{~nm}$ through the glutathione/NADPH/glutathione reductase system by the dismutation of tert-butyl hydroperoxide [17].

Glutathione S-transferase (GST) activity was determined at $340 \mathrm{~nm}$ using CDNB (1-chloro-2, 4-dinitrobenzene) as substrate and a $0.15 \mathrm{M}$ GSH concentration [18].

Finally, glutathione reductase (GR) activity was assayed at $340 \mathrm{~nm}$ by measuring the rate of NADPH oxidation [19]. Results were expressed as $\mathrm{mmol}^{-1} \mathrm{~g}^{-1}$ (CAT) and $\mu \mathrm{mol}$ $\min ^{-1} \mathrm{~g}^{-1}$ (GPx, GST, and GR).

\subsection{Nonenzymatic antioxidants}

Nonprotein thiols, mostly present as the reduced form of glutathione (GSH), were measured at $412 \mathrm{~nm}$ according to Beutler using Elmann's reagent (DTNB: 2-dithionitrobenzoic acid) [20]. Immediately after thawing, acid extracts were obtained by adding tissue portions to $12 \%$ trichloroacetic acid $(1: 4 \mathrm{w} / \mathrm{v})$, which were then centrifuged at $15000 \mathrm{~g}$ for $5 \mathrm{~min}$ utes at $5^{\circ} \mathrm{C}$. Supernatants from the acid extracts were added to a buffer containing $0.25 \mathrm{mM}$ DTNB in $0.1 \mathrm{M} \mathrm{Na}_{2} \mathrm{PO}_{4}, \mathrm{pH}$ 8.0 , and the formation of the thiolate anion was immediately determined. Total glutathione (TG) was also measured at $412 \mathrm{~nm}$ in acid extracts according to the enzymatic method of Tietze [21]. Oxidized glutathione (GSSG) was also determined by calculating the difference (in equivalents of GSH) between total glutathione and reduced glutathione contents. Results were expressed as $\mu \mathrm{mol} \mathrm{g}^{-1}$.

\subsection{Myeloperoxidase activity}

Myeloperoxidase activity was measured according to the method developed by Rao et al., and was estimated by colorimetric measurement at $450 \mathrm{~nm}$ on an Elisa plate reader [22]. Results were expressed as $\mathrm{mU} / \mathrm{mL}$. 
TABLE 1: Biomarkers of oxidative stress in gingival tissue of healthy control and individuals with periodontal disease. The results are represented by means \pm SEM of controls (healthy individuals) and patients with periodontal diseases $(\mathrm{E})$. CAT $=$ Activities of Catalase, GPx $=$ glutathione peroxidase, GST = glutathione S-transferase, GR = glutathione reductase, $\mathrm{MPO}=$ myeloperoxidase, $\mathrm{TG}=$ total glutathione, $\mathrm{GSH}$ = glutathione.

\begin{tabular}{lccc}
\hline & Control & Experimental & $P$ \\
\hline CAT $\left(\mathrm{mmol} \mathrm{min}^{-1} \mathrm{~g}^{-1}\right)$ & $1.64 \pm 0.46$ & $2.00 \pm 0.30$ & .523 \\
GPx $\left(\mu \mathrm{mol} \mathrm{min} \mathrm{m}^{-1}\right)$ & $0.80 \pm 0.11$ & $2.09 \pm 0.34$ & $.006^{* * *}$ \\
GST $\left(\mu \mathrm{mol} \mathrm{min} \mathrm{g}^{-1}\right)$ & $4.28 \pm 0.89$ & $10.81 \pm 0.63$ & $.001^{* * *}$ \\
GR $\left(\mu \mathrm{mol} \mathrm{min} \mathrm{g}^{-1}\right)$ & $0.28 \pm 0.04$ & $0.22 \pm 0.06$ & .481 \\
MPO $\left(\mathrm{mU} / \mathrm{mL}^{-1}\right)$ & $222.20 \pm 54.00$ & $556.44 \pm 76.77$ & $.003^{* * *}$ \\
TG $\left(\mu \mathrm{mol} \mathrm{g}{ }^{-1}\right)$ & $0.44 \pm 0.11$ & $0.63 \pm 0.09$ & .171 \\
GSH $\left(\mu \mathrm{mol} \mathrm{g}^{-1}\right)$ & $0.38 \pm 0.08$ & $0.46 \pm 0.06$ & .459 \\
SSG $\left(\mu \mathrm{mol} \mathrm{g}^{-1}\right)$ & $0.06 \pm 0.01$ & $0.17 \pm 0.04$ & $.019^{* * *}$ \\
TBARS $\left(\mathrm{nmol} \mathrm{g}^{-1}\right)$ & $113.07 \pm 16.59$ & $188.80 \pm 20.73$ & $.015^{* * *}$ \\
\hline
\end{tabular}

*** $(P<.001)$ mean statistical differences between controls and experimental group.

\subsection{Lipoperoxidation assay}

Thiobarbituric acid-reactive substance (TBARS) contents were determined to assess endogenous lipid oxidation in gingival tissue according to Ohkawa et al. [23] and Bird and Draper [24]. After thawing, gingival portions were immediately added to $12 \%$ trichloroacetic acid $(1: 4 \mathrm{v} / \mathrm{v})$ and were then centrifuged at $15000 \mathrm{~g}$ for 5 minutes at $5^{\circ} \mathrm{C}$. Supernatants were added to $50 \mathrm{mM}$ Tris- $\mathrm{HCl} \mathrm{pH} \mathrm{7.0,} \mathrm{vortexed}$ for 20 seconds, added to $0.67 \%(\mathrm{w} / \mathrm{v}) 2$-thiobarbituric acid, maintained in boiling water for 60 minutes, cooled at $5^{\circ} \mathrm{C}$ for 30 minutes, and then analyzed spectrophotometrically at $535 \mathrm{~nm}$. Concentrations were expressed as nmol TBARS/g wet tissue using $\in_{535}=153 \mathrm{mM}^{-1} \mathrm{~cm}^{-1}$.

All the biochemical parameters described above were measured in duplicate, except for the TBARS determinations, which were measured in triplicate.

\section{STATISTICAL ANALYSIS}

The results were expressed as mean \pm SEM. Statistical differences between groups were determined by independent Student $t$ test analysis. For all analyses, $P<.05$ was used to assess overall differences.

\section{RESULTS}

\subsection{Antioxidant enzyme activities}

These results show that there were no significant differences in catalase activity in the experimental group (E) compared to the control group $(P=.523)$. However, a significant increase in GPx activities in the experimental group when compare to the control group $(P=.006)$ was detected (see Table 1). Furthermore, in the experimental group, a significant increase of glutathione S-transferase (GST) values compared to the control group $(P=.001)$ was also observed (see Table 1). The analysis of glutathione reductase (GR) revealed no differences between the studied groups $(P=.481)$ (see Table 1).

\subsection{Myeloperoxidase activity}

The myeloperoxidase activity revealed a significant increase of this inflammatory biomarker in the experimental group $(P=.003)($ see Table 1$)$.

\subsection{Nonenzymatic antioxidant defenses}

In relation to the total glutathione (TG) and the reduced glutathione (GSH) contents, no differences in the values of the experimental group compared to the control group were found $(P>.05)$ (Table 1). However, the values obtained for oxidized glutathione (GSSG) showed a significant increase in the experimental group when compared to the control group $(P=.019)($ see Table 1$)$.

\subsection{Measurement of tissue lipoperoxidation}

Lipoperoxidation was measured through TBARS contents, which were significantly a higher increase in the experimental group $(P=.015)$ (see Table 1$)$.

\section{DISCUSSION}

Few studies have considered the effect of the imbalance between oxidants and antioxidants in patients with periodontitis, which in turn predisposes such individuals to the damaging effects of ROS in the periodontium [25]. Ellis and collaborators analyzed gingival tissues from patients with severe periodontal disease and showed that the activity of catalase was decreased [26]. In the present study, the activity of catalase was not different when the experimental and control groups were compared. One possible explanation for these different responses is that the patients with periodontal disease were in distinct stages of the disease. In this regard, it is well known that the antioxidant responses found in different pathologies depend on the severity or extension suffered by the patients, and long-term chronic conditions may have jeopardized the antioxidant defenses [8].

The analysis of the enzyme glutathione peroxidase revealed a significant increase in the experimental group. 
A GPx increase in gingival samples from dogs and humans with periodontal disease has already been described $[6,27]$. The GPx increase may represent possible antioxidant compensation in detoxification reactions of organic peroxides produced during oxidative stress in gingival tissue [28].

Furthermore, glutathione S-transferase (GST) also revealed a significant increase in its activities in the experimental group. Since GST has a direct role in the neutralization of hydroperoxides derived from the lipoperoxidation processes, increases in GST activities are probably related to the oxidative stress caused by the periodontal inflammatory process $[8,29]$. GST comprises a group of enzymes that are also able to detoxify a variety of compounds including xenobiotics derived from pathogenic microorganisms, catalyzing their conjugation with GSH [30]. Hence, increases in GST activities are excellent indicators of endogenous detoxification from exogenous sources [31].

The enzyme glutathione reductase (GR) has an important accessory antioxidant function related to glutathione peroxidase and glutathione S-transferase. GR intervention continuously regenerates GSH from GSSG in the presence of NADPH, therefore preventing cellular loss of GSH [32]. However, in the current study, no differences in GR activities were detected in gingival tissue between the two groups.

The ubiquitous tripeptide glutathione (GSH) acts directly as a generic ROS scavenger or as a cofactor of GPX and GST, either by catalyzing the reduction of hydrogen peroxide and lipid hydroperoxides or by the conjugation/excretion processes of the so-called Phase II reactions [31]. Total and reduced glutathione revealed a tendency to increase, but the values were not significantly different in patients with periodontitis compared to the controls.

Despite GSH, these results suggest a de novo synthesis of glutathione, which is extremely necessary for the homeostasis of cells [31]. Some periodontopathogenic bacteria deplete GSH, and this may explain the amount of this antioxidant was not elevated in the gingival tissue of patients with periodontitis combined with an increase of the GPx activity in the affected tissue $[33,34]$. A similar result was obtained in gingival tissue and blood, but lower levels of GSH were detected in the crevicular gingival fluid of patients with chronic periodontitis, when compared to normal subjects $[27,35]$.

On the other hand, a significant increase in GSSG concentrations was detected in the experimental group, which is a clear biomarker of oxidative stress detected in inflammatory processes linked to periodontitis. Nevertheless, Chapple et al. (2002) found less GSSG in gingival cervical fluid of patients with chronic periodontitis [35]. Consistent with the results for GSSG, tissue lipoperoxidation, measured as TBARS contents in the gingival tissue, also displayed a significant increase $(P=.015)$ in individuals affected by periodontitis, and oxidative stress, in the gingival tissue associated with periodontal disease [36].

The systemic depletion of antioxidants clearly indicates that in chronic periodontitis the antioxidant system is affected by a relatively strong oxidation insult, which can also deplete nutritional antioxidants such as vitamin $\mathrm{E}$ and $\mathrm{C}$ in plasma and also vitamin $\mathrm{E}$ in red cell membrane [27].
Moreover, myeloperoxidase activity in gingival tissue showed a significant increase in patients with periodontal disease when compared to the control group, an indicative of a chronic inflammatory process also reflected at a systemic level. These results were similar to the measurements obtained from the analysis of crevicular gingival fluid in humans with periodontal disease [37].

Oxidative stress processes and alterations in the immune system are closely related and have been described in different diseases, thus both the aspects also seem to be linked to the pathogenesis of periodontal disease, and can also be detected in the plasma of patients with periodontitis [8, 27, 35]. However, the extent to which ROS overgeneration influences the initiation and progression of periodontal diseases is still unknown.

In conclusion, in spite of the limited number of samples examined in the present study, the results indicate a relationship between proinflammatory and oxidative stress biomarkers and periodontal disease.

\section{ACKNOWLEDGMENT}

This work was supported by grants from the Conselho Nacional de Pesquisa e Desenvolvimento Científico (CNPq) and Coordenação de Aperfeiçoamento de Pessoal de Nível Superior (CAPES, from Brazil for fellowship support).

\section{REFERENCES}

[1] A. Kantarci, K. Oyaizu, and T. E. van Dyke, "Neutrophilmediated tissue injury in periodontal disease pathogenesis: findings from localized aggressive periodontitis," Journal of Periodontology, vol. 74, no. 1, pp. 66-75, 2003.

[2] V. Baelum and R. Lopez, "Periodontal epidemiology: towards social science or molecular biology?" Community Dentistry and Oral Epidemiology, vol. 32, no. 4, pp. 239-249, 2004.

[3] M. Battino, M. S. Ferreiro, J. L. Quiles, S. Bompadre, L. Leone, and P. Bullon, "Alterations in the oxidation products, antioxidant markers, antioxidant capacity and lipid patterns in plasma of patients affected by Papillon-Lefevre syndrome," Free Radical Research, vol. 37, no. 6, pp. 603-609, 2003.

[4] R. J. Waddington, R. Moseley, and G. Embery, "Reactive oxygen species: a potential role in the pathogenesis of periodontal diseases," Oral Diseases, vol. 6, no. 3, pp. 138-151, 2000.

[5] H. Katsuragi, M. Ohtake, I. Kurasawa, and K. Saito, "Intracellular production and extracellular release of oxygen radicals by PMNs and oxidative stress on PMNs during phagocytosis of periodontopathic bacteria," Odontology, vol. 91, no. 1, pp. 13-18, 2003.

[6] U. Sakallioğlu, E. Aliyev, Z. Eren, G. Akşimşek, I. Keskiner, and Ü. Yavuz, "Reactive oxygen species scavenging activity during periodontal mucoperiosteal healing: an experimental study in dogs," Archives of Oral Biology, vol. 50, no. 12, pp. 1040-1046, 2005.

[7] M. Takane, N. Sugano, H. Iwasaki, Y. Iwano, N. Shimizu, and K. Ito, "New biomarker evidence of oxidative DNA damage in whole saliva from clinically healthy and periodontally diseased individuals," Journal of Periodontology, vol. 73, no. 5, pp. 551554, 2002.

[8] B. Halliwell and J. M. C. Gutteridge, "Free radicals, other reactive species and disease," in Free Radicals in Biology and Medicine, pp. 617-783, Clarendon Press, Oxford, UK, 1998. 
[9] M. L. Wang, P. V. Hauschka, R. S. Tuan, and M. J. Steinbeck, "Exposure to particles stimulates superoxide production by human THP-1 macrophages and avian HD-11EM osteoclasts activated by tumor necrosis factor- $\alpha$ and PMA," Journal of Arthroplasty, vol. 17, no. 3, pp. 335-346, 2002.

[10] I. L. Chapple, "Role of free radicals and antioxidants in the pathogenesis of the inflammatory periodontal diseases," Clinical Molecular Pathology, vol. 49, no. 5, pp. 247-255, 1996.

[11] M. Fratelli, L. O. Goodwin, U. A. Ørom, et al., "Gene expression profiling reveals a signaling role of glutathione in redox regulation," Proceedings of the National Academy of Sciences of the United States of America, vol. 102, no. 39, pp. 13998-14003, 2005.

[12] T. Honda, H. Domon, T. Okui, K. Kajita, R. Amanuma, and K. Yamazaki, "Balance of inflammatory response in stable gingivitis and progressive periodontitis lesions," Clinical and Experimental Immunology, vol. 144, no. 1, pp. 35-40, 2006.

[13] D. V. Sculley and S. C. Langley-Evans, "Salivary antioxidants and periodontal disease status," Proceedings of the Nutrition Society, vol. 61, no. 1, pp. 137-143, 2002.

[14] J. Lindhe, "Interation between parasite and Human in the periodontal disease," in Text Book Clinic Periodontology and Oral Implantology, pp. 148-175, Guanabara Koogan, Rio de Janeiro, Brasil, 2005.

[15] J. Lindhe, "Peridontal surgery: surgical acess," in Text Book Clinic Periodontology and Oral Implantology, pp. 502-556, Guanabara Koogan, Rio de Janeiro, Brasil, 2005.

[16] H. Aebi, "Catalase in vitro," Methods in Enzymology, vol. 105, pp. 121-126, 1984.

[17] L. Flohé and W. A. Gunzler, "Assays of glutathione peroxidase," Methods in Enzymology, vol. 105, pp. 114-121, 1984.

[18] W. H. Habig, M. J. Pabst, and W. B. Jakoby, "Glutathione Stransferases: the first enzymatic step in mercapturic acid formation," Journal of Biological Chemistry, vol. 249, no. 22, pp. 7130-7139, 1974.

[19] I. Carlberg and B. Mannervik, "Glutathione reductase," in Methods in Enzymology, A. Meiste, Ed., pp. 484-490, Academic Press, New York, NY, USA, 1993.

[20] E. Beutler, "The preparation of red cells for assay," in Red Cell Metabolism: A Manual of Biochemical Methods, E. Beutler, Ed., pp. 8-18, Grune and Straton, New York, NY, USA, 1975.

[21] F. Tietze, "Enzymic method for quantitative determination of nanogram amounts of total and oxidized glutathione: applications to mammalian blood and other tissues," Analytical Biochemistry, vol. 27, no. 3, pp. 502-522, 1969.

[22] T. S. Rao, J. L. Currie, A. F. Shaffer, and P. C. Isakson, "Comparative evaluation of arachidonic acid (AA)- and tetradecanoylphorbol acetate (TPA)-induced dermal inflammation," Inflammation, vol. 17, no. 6, pp. 723-741, 1993.

[23] H. Ohkawa, N. Ohishi, and K. Yagi, "Assay for lipid peroxides in animal tissues by thiobarbituric acid reaction," Analytical Biochemistry, vol. 95, no. 2, pp. 351-358, 1979.

[24] R. P. Bird and H. H. Draper, "Comparative studies on different methods of malonaldehyde determination," Methods in Enzymology, vol. 105, pp. 299-305, 1984.

[25] G. R. Brock, C. J. Butterworth, J. B. Matthews, and I. L. Chapple, "Local and systemic total antioxidant capacity in periodontitis and health," Journal of Clinical Periodontology, vol. 31, no. 7, pp. 515-521, 2004.

[26] S. D. Ellis, M. A. Tucci, F. G. Serio, and R. B. Johnson, "Factors for progression of periodontal diseases," Journal of Oral Pathology and Medicine, vol. 27, no. 3, pp. 101-105, 1998.

[27] K. Panjamurthy, S. Manoharan, and C. R. Ramachandran, "Lipid peroxidation and antioxidant status in patients with pe- riodontitis," Cellular \& Molecular Biology Letters, vol. 10, no. 2, pp. 255-264, 2005.

[28] K. H. Cheeseman and T. F. Slater, "An introduction to free radical biochemistry," British Medical Bulletin, vol. 49, no. 3, pp. 481-493, 1993.

[29] A. J. Oakley, "Glutathione transferases: new functions," Current Opinion in Structural Biology, vol. 15, no. 6, pp. 716-723, 2005.

[30] Y. Sagara, R. Dargusch, D. Chambers, J. Davis, D. Schubert, and P. Maher, "Cellular mechanisms of resistance to chronic oxidative stress," Free Radical Biology and Medicine, vol. 24, no. 9, pp. 1375-1389, 1998.

[31] B. Halliwell and J. M. C. Gutteridge, "The chemistry of free radicals and related reactive species," in Free Radicals in Biology and Medicine, pp. 36-104, Clarendon Press, Oxford, UK, 1999.

[32] G. Noctor and C. H. Foyer, "Ascorbate and gluthatione: keeping active oxygen under control," Annual Review of Plant Physiology and Plant Molecular Biology, vol. 49, pp. 249-279, 1998.

[33] J. Carlsson, J. T. Larsen, and M. B. Edlund, "Peptostreptococcus micros has a uniquely high capacity to form hydrogen sulfide from glutathione," Oral Microbiology and Immunology, vol. 8, no. 1, pp. 42-45, 1993.

[34] J. Carlsson, J. T. Larsen, and M. B. Edlund, "Utilization of glutathione (L- $\gamma$-glutamyl-L-cysteinylglycine) by Fusobacterium nucleatum subspecies nucleatum," Oral Microbiology and Immunology, vol. 9, no. 5, pp. 297-300, 1994.

[35] I. L. C. Chapple, G. Brock, C. Eftimiadi, and J. B. Matthews, "Glutathione in gingival crevicular fluid and its relation to local antioxidant capacity in periodontal health and disease," Journal of Clinical Pathology, vol. 55, no. 6, pp. 367-373, 2002.

[36] B. Halliwell and J. M. C. Gutteridge, "Detection of free radicals and other reactive species: trapping and fingerprinting," in Free Radicals in Biology and Medicine, pp. 393-412, Clarendon Press, Oxford, UK, 1999.

[37] P.-F. Wei, K.-Y. Ho, Y.-P. Ho, Y.-M. Wu, Y.-H. Yang, and C.C. Tsai, "The investigation of glutathione peroxidase, lactoferrin, myeloperoxidase and interleukin- $1 \beta$ in gingival crevicular fluid: implications for oxidative stress in human periodontal diseases," Journal of Periodontal Research, vol. 39, no. 5, pp. 287-293, 2004. 


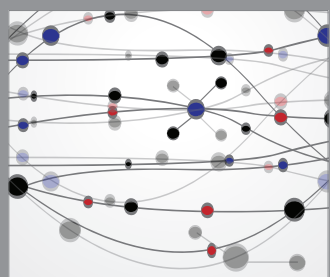

The Scientific World Journal
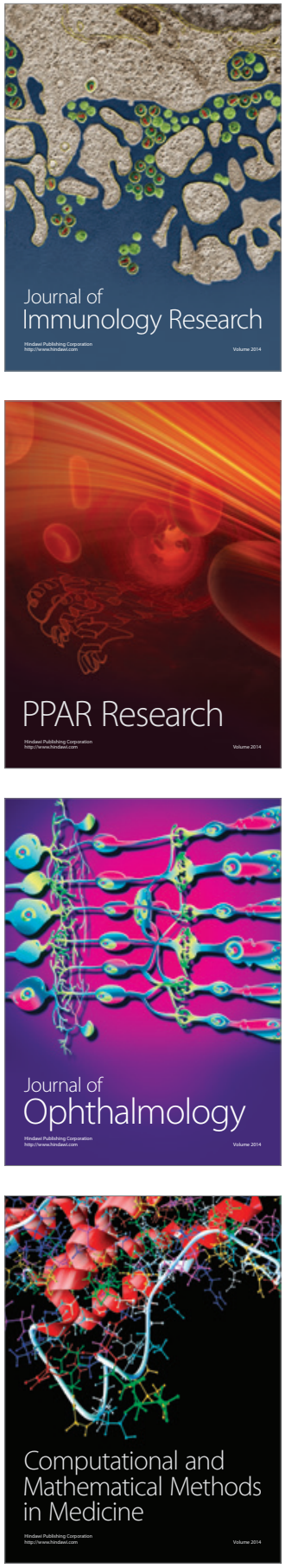

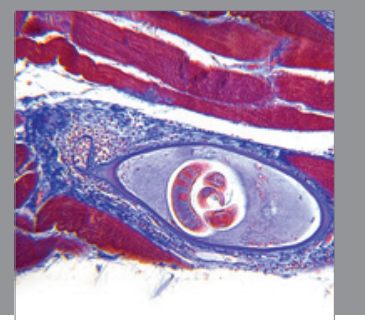

Gastroenterology

Research and Practice
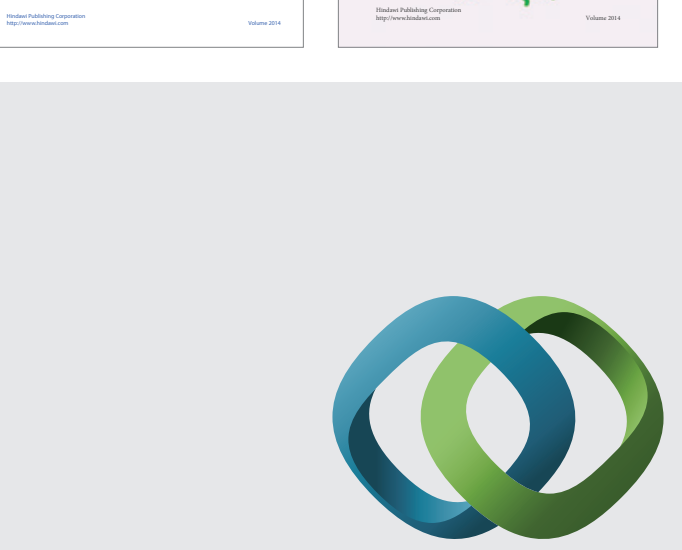

\section{Hindawi}

Submit your manuscripts at

http://www.hindawi.com
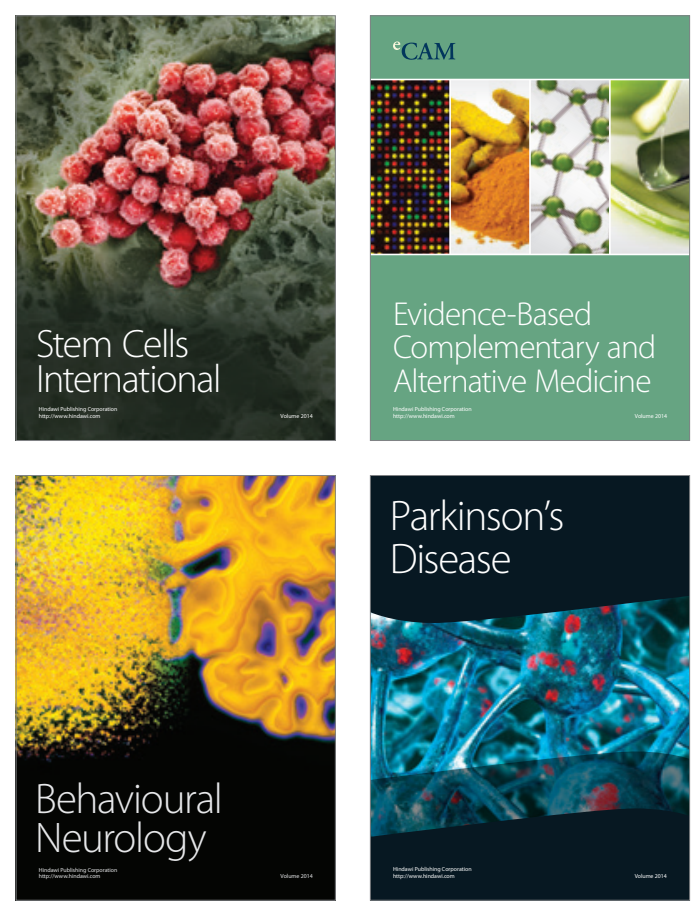

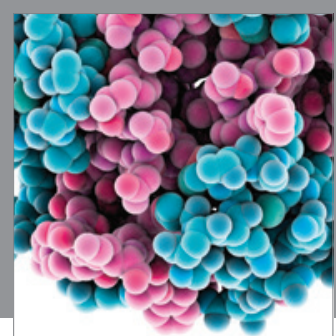

Journal of
Diabetes Research

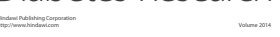

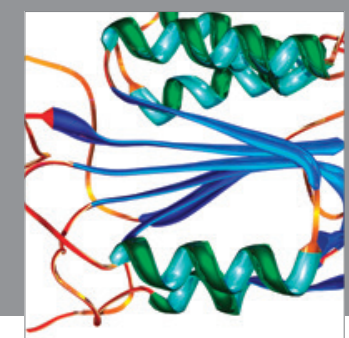

Disease Markers
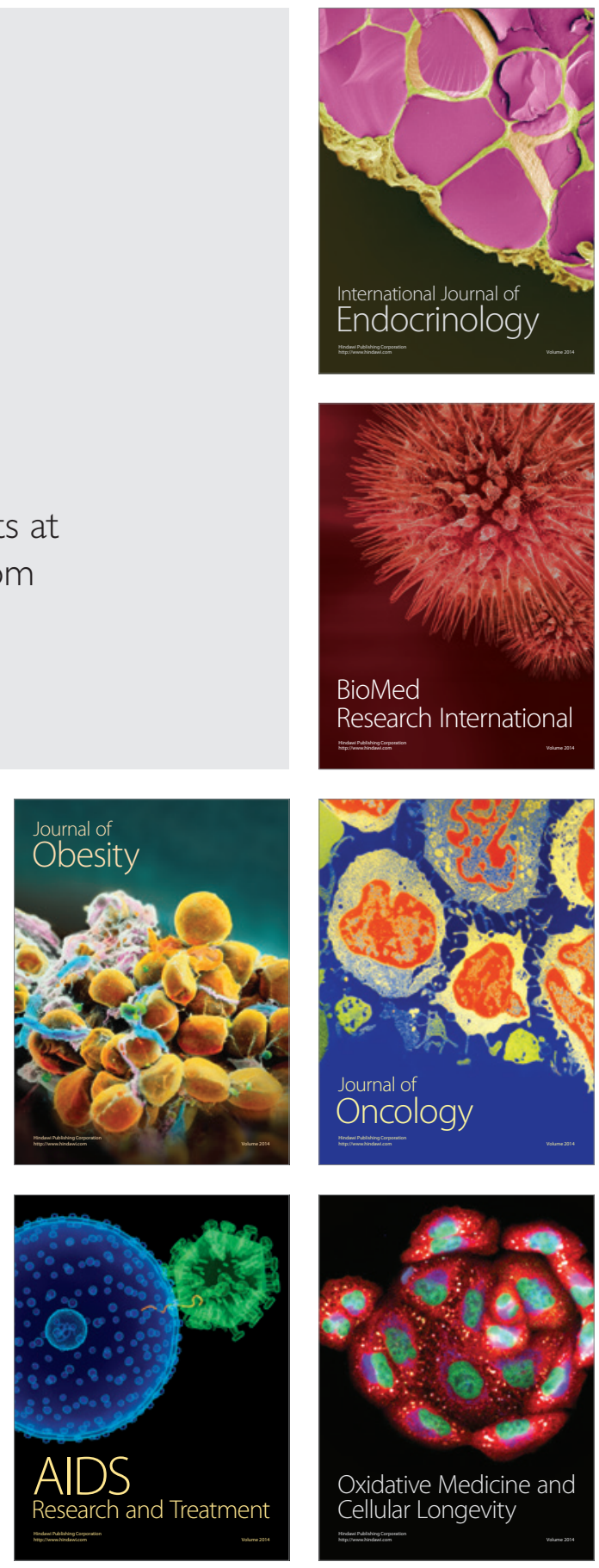